\title{
МЕТОДЫ ОПРЕДЕЛЕНИЯ ПОСТАВЩИКОВ И НАЧАЛЬНОЙ ЦЕНЫ В СИСТЕМЕ ГОСУДАРСТВЕННЫХ ЗАКУПОК РОССИЙСКОЙ ФЕДЕРАЦИИ
}

\author{
(C) 2020 Хромов Иван Евгеньевич \\ кандидат экономических наук, старший научный сотрудник, \\ Лаборатория микроэкономического анализа и моделирования \\ Центральный экономико-математический институт РАН, Россия, Москва \\ E-mail: khromov_gaugn@mail.ru
}

В Российской Федерации постоянно совершенствуется система государственных закупок.

Для осуществления процесса государственных закупок необходим обоснованный выбор поставщиков (подрядчиков, исполнителей) и начальной цены государственного контракта.

В данной работе описаны методы, при помощи которых могут быть определены поставщики (подрядчики, исполнители) и начальная цена в системе государственных закупок.

Ключевые слова: Сокращение издержек, управление предприятием, финансовое планирование, закупки, партнёрство, прогнозирование, задача выбора, выбор поставщика, выбор подрядчика, выбор исполнителя, определение начальной цены, государственные закупки

Для формирования плана-графика закупки, извещения о её осуществлении и подготовки документации по ней необходимо определить начальную (максимальную) цену контракта НМЦК.

НМЦК - высшая (максимальная) цена или другими словами - верхний предел, указанный заказчиком в извещении, документации о закупке и приглашении принять участие в закупке, по которому в будущем будет заключен контракт.

Закон № 44-ФЗ регламентирует правила по ее определению, они отражены в части 1 статьи 22 Закона о закупках. Итак, цена контракта, а также цена контакта, который заключается с единственным поставщиком (подрядчиком, исполнителем), определяются и обосновываются заказчиком с помощью методов, представленных на рис. 1 [1].

Законом предусмотрено применение иных методов в ситуации, когда использование вышеперечисленных методов для определения НМЦК невозможно. В этой ситуации заказчику необхо-

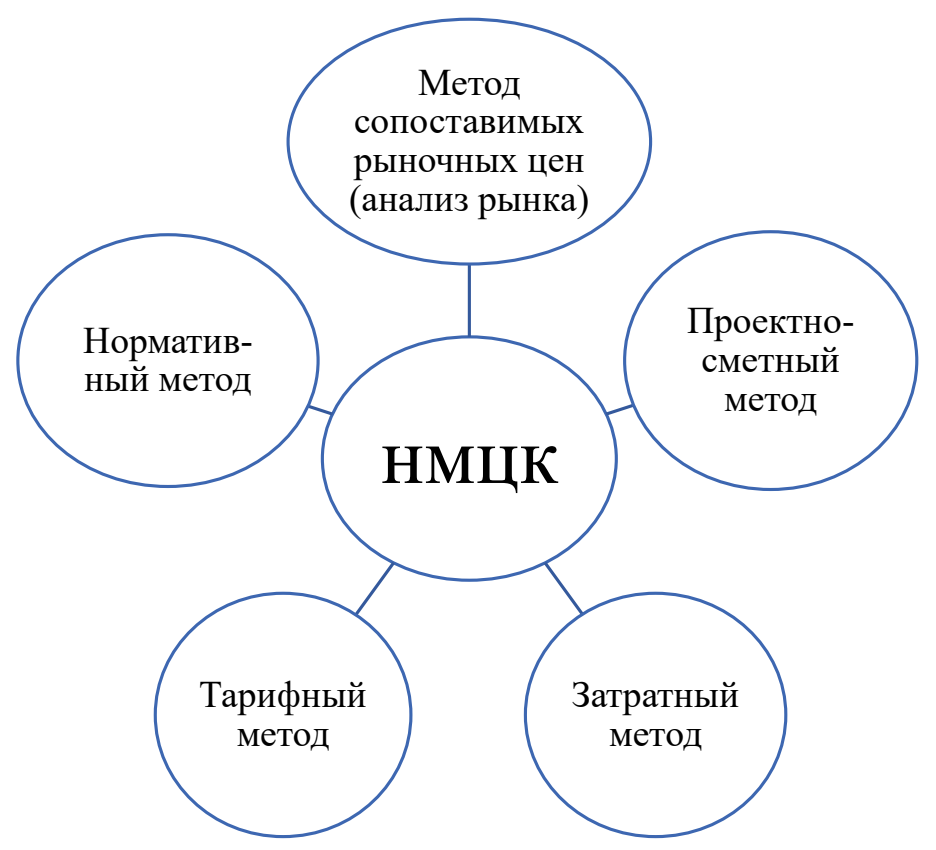

Рuc. 1. Методы определения НМЦК 
димо подготовить обоснование.

1. Метод сопоставимых рыночных цен (анализа рынка)

При определении и обосновании НМЦК в приоритете выбора у заказчиков среди существующих методов всегда будет метод сопоставимых рыночных цен. Он устанавливает начальную (максимальную) цену контракта и цену контракта, который заключается с единственным поставщиком (подрядчиком, исполнителем). Его особенность заключается в том, что цена основана на анализе рыночных цен на идентичные товары (работы, услуги), которые планируются к закупке. Следует отметить, что в случае отсутствия информации о ценах на такие товары, заказчик вправе использовать цены на однородные товары (работы, услуги) [6]. Суть таких определений как идентичность и однородность продукции отражена в ст. 22 Закона № 44Ф3 [1].

При обосновании НМЦК в данном методе необходимо разделить товары (работы, услуги) на категории по идентичности и однородности, а в запросе информации о цене указывать достоверные сведения для ее установления.

Следует отметить, что несоблюдение требования по определению идентичности и однородности может привести к неправильному описанию объекта закупки, что, в свою очередь, послужит признанием закупки недействительной.

Обязательным условием данного метода будет использование как минимум трех вариантов цен на продукцию, которые могут предложить различные поставщики. Информация о рыночных ценах должна быть общедоступна и получена с учетом соответствия условий планируемой закупки с условиями, предложенными при поставке товаров, выполнения работ, оказания услуг, как в плане реализации сроков, так и в финансовых вопросах.

2. Нормативный метод

Использование нормативного метода возможно одновременно с использованием метода сопоставимых рыночных цен. При этом полученная цена не может превышать цену, которая была рассчитана с помощью нормативного метода.

Сам по себе нормативный метод заключается в расчете начальной (максимальной) цены контракта и цены контракта с единственным поставщиком (подрядчиком, исполнителем) на основе требований, установленных к закупаемым товарам, работам, услугам, а также с использованием информации о предельных ценах на них, которая размещена в ЕИС.

3. Тарифный метод

Данный метод будет использоваться заказчиком, если цены закупаемых товаров, работ, услуг для обеспечения государственных и муниципальных нужд подлежат государственному регулированию или установлены муниципальными правовыми актами. В этом случае цены (тарифы) на товары, работы, услуги будут оказывать влияние на начальную (максимальную) цену контракта и цену контракта, который заключается с единственным поставщиком (подрядчиком, исполнителем).

4. Проектно-сметный метод

Метод применяется заказчиком для определения начальной (максимальной) цены контракта, цены контракта, который заключается с единственным поставщиком (подрядчиком, исполнителем) в следующих случаях:

1) при проведении капитального ремонта, строительстве и реконструкции объектов капитального строительства;

2) при осуществлении текущего ремонта зданий, строений, сооружений и помещений;

3) при проведении работ по сохранению объектов культурного наследия (памятников истории и культуры) народов РФ. Исключением будут являться научно-методическое руководство, технический и авторский надзоры [5].

При обосновании НМЦК в данном методе используется проектная документация (вместе со сметной стоимостью работ), сведения о ценах, рассчитанных по индекс-дефляторам в соответствии с видами экономической деятельности, а также используется положение о порядке проверки достоверности определения сметной стоимости объектов капитального строительства, которые финансируются за счет средств из федерального бюджета, и информация о капитальных вложениях, объемы которых необходимы для реализацию инвестиционных проектов в соответствии с инвестиционной программой [4].

5. Затратный метод

Данный метод заключается в определении начальной (максимальной) цены контракта, цены контракта, заключаемого с единственным поставщиком (подрядчиком, исполнителем), как суммы произведенных затрат и обычной для определенной сферы деятельности прибы- 
ли. При этом учитываются обычные в подобных случаях прямые и косвенные затраты на производство или приобретение и (или) реализацию товаров, работ, услуг, затраты на транспортировку, хранение, страхование и иные затраты.

После того, как метод по расчету начальной (максимальной) цены контракта был выбран, заказчик получил ее значение, можно сделать прогноз о возможных ситуациях, которые могут произойти в зависимости от того, какой результат был получен.

В случае, если НМЦК занижена, одним из последствий будет то, что процедура по проведению закупки может вовсе не состояться, т.к. потенциальный подрядчик маловероятно захочет заключать контракт себе в убыток. Также велика вероятность того, что этот самый подрядчик окажется недобросовестным: качество поставляемого товара, выполняемой работы или оказываемой услуги могут быть низкими из-за экономии подрядчика (поставщика) или же он не до конца выполнит свои контрактные обязательства.

В случае, когда НМЦК завышена, затраченные средства на проведение закупочной процедуры будут высоки, значит, что можно будет говорить о неэффективном расходовании средств из бюджета. Ход торгов может измениться в сторону снижения размера цены закупки до среднерыночной.

В том случае, если НМЦК определена корректно, можно говорить о сложившейся благоприятной ситуации для заказчика и потенциального подрядчика, участие в этой закупке будет взаимовыгодным для всех участников. Средства из бюджета будут израсходованы эффективно, а товары, работы и услуги будут надлежащего качества [6].

Модель выбора поставщика строится в соответствии с Законом № 44-ФЗ. На её основе заказчик может выбрать для себя наиболее оптимальный вариант, исходя из таких влияющих факторов как начальная (максимальная) цена контракта и оценка предложений на рынке. Так, закон регламентирует несколько способов выбора поставщика (подрядчика, исполнителя), представленных на рис. 2 [1].

Существует два способа осуществления закупочных процедур: заказчик выбирает либо конкурентный способ по определению поставщика (подрядчика, исполнителя), либо выбирает проведение закупки у единственного поставщика (подрядчика, исполнителя).

В сфере закупочной деятельности под конкурсом понимают такой способ определения поставщика (подрядчика, исполнителя), при котором участник закупки, предложивший наиболее выгодные заказчику условия по исполнению контракта, будет являться победителем. Если информация о закупке доступна всем потенциальным участникам закупки, в ЕИС размещены извещение о проведении конкурса и конкурсная документация, а все участники должны соответствовать единым требованиям, то такой конкурс будет называться открытым.

В закрытом конкурсе информация о закупочной процедуре представляет собой государственную тайну. Приглашение принять участие в проведении закупочной процедуры закрытым способом направляется ограниченному кругу лиц. Закрытый конкурс проводится в отношении закупки товаров, работ и услуг, сведения о которых не могут быть распространены в общедоступных источниках или в отношении заключения контрактов на оказание услуг по страхованию, транспортировке и охране ценностей, музейных предметов и музейных коллекций, редких и ценных изданий, рукописей, архивных документов, которые имеют важное историческое, художественное и культурное значение.

Только федеральный орган исполнительной власти, уполномоченный Правительством Российской Федерации на осуществление функций по согласованию применения закрытого способа по определению поставщиков (подрядчиков, исполнителей), может дать разрешение на проведение такого конкурса.

Во всех остальных случаях, за исключением вышеописанных, заказчик при осуществлении закупки руководствуется способом открытого конкурса.

Для этого ему необходимо разработать и утвердить конкурсную документацию, требования к которой установлены Правительством РФ. Привлечение специализированной организации для ее разработки не запрещается. Следует отметить, что с участников открытого конкурса не допустимо взимание какой-либо платы за их участие.

Заявка на участие в открытом конкурсе содержит сведения о цене контракта, качественных и количественных характеристиках товара, услуги, работы; сроках их поставки и расходах на эксплуатацию и техническое обслуживание, 


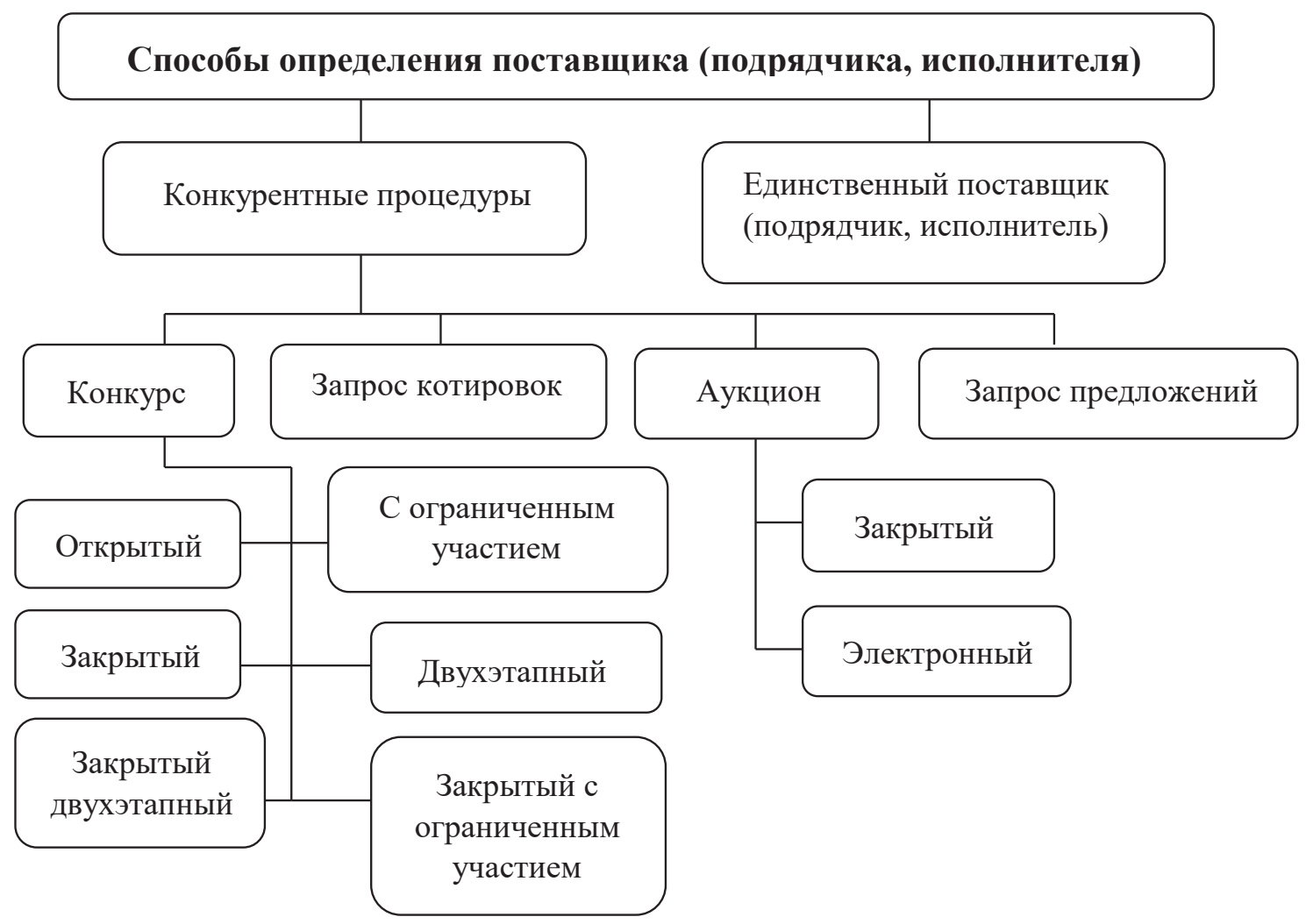

Puc. 2. Модель определения поставщика (подрядчика, исполнителя)

а также об объемах предоставленной гарантии качества продукции.

В извещении о проведении открытого конкурса отражена информация о форме торгов, наименовании, месте нахождения и контактных данных заказчика, предмете контракта с указанием его объема, места поставки и НМЦК. Описывается срок, место и порядок предоставления конкурсной документации, порядке и сроках вскрытия конвертов с заявками на участие в открытом конкурсе, а также о месте и дате их рассмотрения и подведения итогов.

Основаниями для признания конкурса несостоявшимся может послужить тот факт, что была подана только одна заявка на участие или по итогам рассмотрения заявок всем участникам было отказано за исключением одного, или же от заключения контакта отказались участники с первым и вторым порядковыми номерами заявок. В этих случаях заказчик вправе начать повторное проведение конкурса, при этом его условия он может изменить.

Помимо открытого и закрытого конкурса, которые являются стандартными формами участия в закупочной процедуре, существуют другие разновидности способов по определению поставщика. В соответствии с законом о закупках эти формы также могут быть открытыми и закрытыми.

Итак, закон допускает проведение конкурса с ограниченным участием в случае, если можно говорить об инновационности, высокотехнологичности или о специализированном характере поставляемых товаров, выполняемых работ или оказываемых услуг.

При заключении контракта на проведение научных исследований, проектных работ, экспериментов или на поставку инновационной, высокотехнологичной продукции, а также для создания произведений искусства закон предусматривает возможность осуществления двухэтапного конкурса. Он проходит в два этапа, следовательно, участники закупки подают свои заявки два раза. На первом этапе подача заявок осуществляется без указания предложений о цене контракта. Уже на втором этапе, когда все условия закупки уточнены, происходит окончательная подача заявок с указанием цены контракта.

В закрытом двухэтапном конкурсе и закрытом конкурсе с ограниченным участием обобщены вышеописанные требования и условия [2]. 
В отличие от конкурса, где победителем будет являться тот, кто предложит наиболее выгодные условия по исполнению контракта, при осуществлении закупочной деятельности в рамках аукциона победителем будет признан тот, кто предложит наименьшую цену контракта. Аукцион проходит в условиях, где рынок активно функционирует, достаточно развита конкуренция, и сравнение участников закупки происходит по критерию цены.

Всего существует две формы проведения аукциона: закрытая и открытая. Форма открытого аукциона четко обозначена - аукцион в электронной форме. Он осуществляется на электронных торговых площадках, доступ к участию в которых возможен через аккредитацию участников закупки.

Для участия в электронном аукционе необходима подача заявки, которая состоит из двух частей. В первой части заявки содержится согласие участника закупки на поставку товара, оказание услуги, выполнение работы в соответствии с требованиями документации об аукционе и сведениями о характеристике предмета закупки. Эту часть заявки можно дополнить эскизом, рисунком, чертежом или фотографией товара для наглядности необходимого к поставке заказа.

Сведения об участнике закупки содержатся во второй части заявки. Когда все части заявки заполнены, они одновременно направляются на электронную площадку в виде двух электронных документов, подписанных с помощью электронной цифровой подписи, где уже оператор электронной площадки передает их на рассмотрение аукционной комиссии. По итогам ее рассмотрения выносится решение о допуске участника к проведению закупки.

Если же сведения о предмете закупки составляют государственную тайну, то так же, как и в закрытом конкурсе, заказчики направляют ограниченному кругу лиц вместо извещения о проведении закупки приглашение принять участие. Можно говорить в таком случае о проведении аукциона в закрытой и неэлектронной форме [3].

Помимо существования конкурса и аукциона, можно использовать для определения поставщика (исполнителя, победителя) запрос котировок и предложений. В запросе котировок победителем будет признан участник, предложивший наиболее низкую цену контракта, при этом торговаться участникам закупки, как в аукционе, нельзя. Заявка на предмет закупки носит название котировочной. Следует отметить, что в заявке должна быть указана начальная (максимальная) цена контракта, не превышающая 500 тысяч рублей.

Запрос предложений предполагает победу того участника закупки, который представит окончательное предложение, наилучшим образом отвечающее потребностям заказчика на предмет закупки.

Итак, все вышеуказанное относилось к осуществлению закупочных процедур конкурентным способом. В сфере закупочной деятельности заказчик может выбрать проведение закупки у единственного поставщика (подрядчика, исполнителя). Это такой способ по его определению, когда заказчиком предлагается заключение контракта только одному поставщику.

Итак, во второй главе был проведен анализ и подробно изучены основы экономикоматематического моделирования системы государственных закупок в Российской Федерации.

Для достижения поставленных задач были рассмотрены общие принципы моделирования процессов закупочной деятельности, этапы цикла закупок и его основные операции, на основе которых строится модель закупочной процедуры.

Можно сказать, что цикл закупок должен действовать как налаженный механизм, в нем одна операция плавно перетекает в другую, по завершению одного этапа начинается новый. Каждый этап в модели цикла закупок несет в себе свои особенности и требования, выполнение которых должно привести участников закупки к конечной цели и завершающему этапу определение победителя закупки и заключение контракта с последующим его исполнением.

Подводя итог вышесказанному, можно сказать, что осуществление закупки в зависимости от условий многовариантно и исходит из выбора заказчиком, в первую очередь, метода определения начальной (максимальной) цены контракта, во вторую очередь (но не по значимости) - это выбор способа по определению поставщиков (подрядчиков, исполнителей). 


\section{Библиографический список}

1. Федеральный закон от 05.04.2013 г. № 44-Ф3 (в ред. от 02.07.2013) «О контрактной системе в сфере закупок товаров, работ, услуг для обеспечения государственных и муниципальных нужд».

2. Постановление Правительства РФ от 28.11.2013 г. № 1089 «Об условиях проведения процедуры конкурса с ограниченным участием при закупке товаров, работ, услуг для обеспечения государственных и муниципальных нужд».

3. Письмо Федеральной антимонопольной службы и Министерства экономического развития РФ от 27,29 июля 2010 г. № АЦ/24051, 13369-АП/Д22 «О порядке проведения открытых аукционов в электронной форме».

4. Единый отраслевой стандарт закупок (положение о закупке) государственной корпорации по атомной энергии «Росатом» (утв. решением Государственной корпорации по атомной энергии «Росатом» от 7 февраля 2012 г. N 37).

5. Борисов А.Н., Трефилова Т.Н. Комментарий к Федеральному закону от 5 апреля 2013 г. № $44-Ф 3$ «О контрактной системе в сфере закупок товаров, работ, услуг для обеспечения государственных и муниципальных нужд» (постатейный; издание шестое, переработанное и дополненное). М.: Деловой двор, 2019.

6. Костакова E.В.Как заказчики определяют начальную (максимальную) цену контракта / Автономная некоммерческая организация дополнительного профессионального образования «Учебный центр СКБ Контур» / Школа электронных торгов. Интернет-источник - https://school.kontur.ru/publications/1519, 2017. 